\title{
Notes on Behaviour of a Marten in Saskatchewan
}

by George W. Scotter, Canadian Wildlife Service, Edmonton

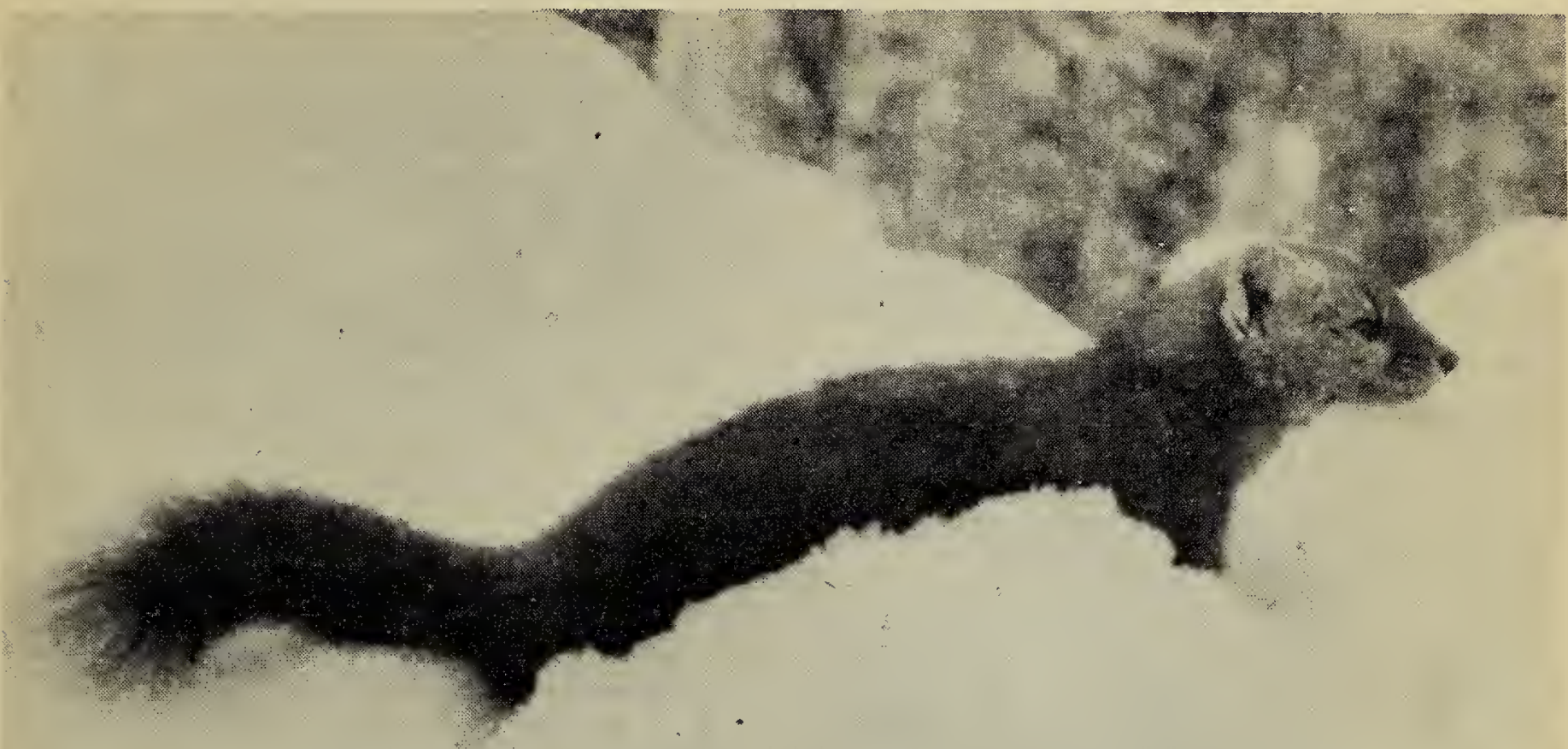

Photo by Canadian Wildlife Service

While studying the effects of forest fires on the barren range of barrenground caribou, Rangifer arcticus, at Chipman Lake in northern Saskatchewan, L. E. Erickson and the writer made a chance observation on the behaviour of the elusive and seldom seen marten, Martes americana. When we were leaving cur tent which was situated in a mature black spruce, Picea mariana, forest, a marten with its distinctive orange throat patch was seen travelling down a game trail towards and about 200 yards from camp. Upon discovering the observers the marten dashed hurriedly up the trail and retreated under a pile of boulders. This marten demonstrated shyness, not "curiosity" or "wary, but unalarmed" behaviour as recorded by Yeager and Remington J. Mamm., 37:521-524, 1956), Halvorsen (J. Mamm., 42:111112, 1961) or Manville (J. Mamm., $112,1961)$. This sighting was made at 7.20 a.m. on August 29, 1960. Skies were overcast and the temperature was near $50^{\circ} \mathrm{F}$.

Use of a boulder pile for escape cover by this arboreal mammal appears to be uncommon although not unreported. Lechleitner (Mammals of Glacier National Park, 1955) re- ported trees were commonly used as avenues for marten retreats in Glacier National Park.

Two days previous to this observation a Chipewyan Indian shot a moose calf near our camp and left the largest portion of a hind leg for our use. After cutting the meat into steak and stew pieces, it was placed in a covered container and stored near camp. On returning from our field work, we discovered that the meat and femur bone which had been placed in a nearby tree had been taken. Bread, bacon and other easily accessible food stuffs had not been disturbed. Presumably the marten seen near camp next morning had purloined meat and bone during our absence which extended from 7.15 a.m. to 7.40 p.m. A marten probably could not eat more than its own weight in meat so a cache may have been established for future use.

The marten observation and probable theft of moose meat by a marten indicates at least some diurnal activity. Some authorities have claimed marten are nocturnal, while others feel they are diurnal. Daytime activity may increase with climatic changes of the fall season. 